\title{
English Proficiency and Sequencing Skills in Narrative Writing of Public High School Students
}

\author{
Lester John T. Quijano ${ }^{1}$ and Ma. Judy B. Legaspi ${ }^{2}$ \\ ${ }^{1}$ Sagay National High School, Sagay City, Philippines \\ ${ }^{2}$ University of Negros Occidental-Recoletos, Bacolod City, Philippines
}

\begin{abstract}
Article history:
Submitted: 25 October 2020

Revised: 13 December 2020

Accepted: 31 December 2020

\section{Keywords:}

Language

English proficiency

Sequencing skills

Narrative writing

Descriptive-comparative

Negros Occidental
\end{abstract}

ABSTRACT. This descriptive-comparative research explored the level of grammar proficiency and sequencing skills in narrative writing of the Grade 7 students. Specifically, it sought to determine the significant difference in the level of grammar proficiency and sequencing skills. The 308 Grade 7 students selected through stratified proportional sampling answered the researcher-made instrument. The findings revealed that the students have a low level of grammar proficiency and average level in sequencing skills as a whole. Moreover, a significant difference exists in the level of grammar proficiency and the level of sequencing skills of students when grouped according to academic performance in English and track, while no significant difference exists when the students are classified according to sex. The results imply that students can sequence events in a narrative. However, they find difficulty in writing grammatically correct sentences. With this, instructional materials may be designed to develop the students' proficiency in writing.

\subsection{Introduction}

The world now is seen as the "Knowledge and Skills Age," where the challenge of education is to prepare learners to deal with the challenges of the changing world. Hence, $21^{\text {st }}$-century learners are expected to possess core knowledge and practical skills that prepare them for the global economy as they plunge into the workforce after graduation (Pederson, 2017). To be globally-competitive individuals, students must first possess the ability to use fluently and effectively the universal language, which is English in both writing and speaking. The use of English in any form of communication opens opportunities regardless of one's color, ethnicity, and background (Rajaendram, 2015).

At school, students are immersed in different learning activities to develop their communicative skills in writing. When acquiring knowledge and sharing it with others, students tend to apply their communicative skills to write comprehensive texts. They must be able to employ proficiency in grammar in their writings. Grammar proficiency refers to the ability to analyze the appropriateness and correctness of a verbal expression with specific reference to grammatical rules (Barraquio, 2015).

Students' logical way of sequencing their thoughts in writing is of great importance (Trapman, Gelderen, Schooten, \& Hulstijn, 2018). In this way, ideas will be clearly stated and understood. Sequencing is a skill that contributes to the students' ability to identify, recall, and express a logical order of events and ideas (Gunther, 2018). Thus, communicative skills in writing require lexical knowledge and knowledge of grammatical rules (Leikin, Ibrahim, \& Eghbaria, 2014; Verhoeven, 2004) and knowledge on how to organize and sequence linguistic units to convey a message.

Unfortunately, despite the educational efforts exerted by classroom teachers, students still face difficulties in writing (Alliance for Excellent Education, 2006; Hofman, Spijkerboer, \& Timmermans, 2009; Salahu-Din, Persky, \& Miller, 2008). These writing difficulties are due to students' lack of vocabulary, poor knowledge and understanding of grammatical structures (Farroq, 2012), and inability to sequence ideas logically and chronologically (Pyykkonen \& Jarviki, 2012).

Several studies have probed on students' writing proficiency and acknowledged that students lack sufficient writing skills due to poor knowledge of grammatical structures (Saddler \& Graham, 2007 cited in Trapman et al., 2018) and sentence cohesions (Ghasemi, 2013). However, studies focusing on the sequencing skills and the difference in the writing and grammar proficiency of highachieving and low-achieving students are scarce. These differences are significant for the educational leaders to direct specific interventions to a group of students to foster proficiency in grammar and sequencing skills in writing.

These concerns prompted the researcher to investigate the grammar proficiency and sequencing skills in narrative writing of Grade 7 students of Sagay National High School - Main, for the School Year 2018-2019. Further, the study sought to determine if there is a significant difference in the level of grammar proficiency and sequencing skills as a whole and grouped according to academic 
performance in English, sex, and track. This research study ventured to add to the scarce literature in learner corpora researches. As an output of this study, the researcher sought to design instructional materials containing the necessary contents and activities that will develop students' grammar proficiency and sequencing skills and enhance their skills in writing different types of texts based on the English 7 curriculum guide.

\subsection{Framework of the Study}

This study assumed that grammar proficiency and sequencing skills are factors of success in narrative writing. Writing proficiency is the measure of academic and professional success (Kellogg \& Raulerson, 2007, cited in Maniego, 2016). This is achieved if the students grasp the grammatical rules and the ability to sequence ideas logically. Michael Halliday's Theory of Functional Grammar (1973) and Noam Chomsky's Transformational-Generative Grammar Theory (1956) are relevant to this study. The theory of functional grammar views language as an interrelated option in making meaning. Language is viewed as functional for the structure of a language is best analyzed and understood concerning each word's functions. Therefore, in constructing meaning out of the text, semantic, syntactic, and pragmatic functions are considered (Halliday, 1973). Halliday's theory of Functional Grammar explains how written texts express meaning and how the sources of language are systematically organized in free and open systems and functionality bound to meaning. The principal aim of functional grammar is to present the grammatical system as a source for making meaning (Halliday, 1973); thus, grammar is not just systemic, but systemic functional.

In connection to Halliday's theory of functional grammar, Noam Chomsky's TransformationalGenerative Grammar Theory (1956) is a system of language analysis that emphasizes the relationship among the elements of a sentence. Further, it tries to show the system of rules that students use in forming grammatical sentences (Mao, 2012). Transformational- Generative Grammar Theory considers the importance of language competence to create and understand newly generated sentences derived from grammatical knowledge (Kyle, 2016). Grammar helps shape utterances, sets boundaries for what is acceptable, and ensures that what is expressed is understood. Therefore, sentences are composed and structured based on acceptable grammatical systems (Maniego, 2016; Kyle, 2016).

The theories on Functional Grammar and Transformational-Generative Grammar are relevant to this research study since both emphasize grammatical competence, knowledge, and proficiency in constructing grammatically correct sentences. The researcher adopts the notion of grammar proficiency as knowledge of grammatical rules as Moghtadi et al. (2014) posited that lexical and syntactic knowledge is the clearest example to represent grammar proficiency. The knowledge of grammatical rules and the ability to sequence ideas shall be applied in writing any kind of text.

\subsection{Methods}

This study used a descriptive-comparative research design. Descriptive research was used to collect data relevant to the level of grammar proficiency and level of sequencing skills of the students. On the other hand, the comparative research design was utilized to establish significant differences in the level of grammar proficiency and sequencing skills of the students when grouped according to the variables of academic performance in English, sex, and track.

The respondents of the study were the Grade 7 students of Sagay National High School enrolled during the School Year 2018 - 2019. The Grade 7 populace consists of four (4) programs - Regular class; Science, Technology, Engineering and Mathematics (STEM); Special Program in the Arts (SPA); and Strengthened Technical Vocational Education Program (STVEP). Since SNHS - Main has 1,544 Grade 7 students, stratified proportional sampling was used. The sample size obtained was 308.

Moreover, the study used a researcher-made instrument, a test paper divided into two parts. The first part lets the students fill out data for demographic profiling. In contrast, the second part is a narrative writing activity and sequencing activity. In the narrative writing activity, a set of pictures was provided in the test instrument, which served as the students' guide in constructing their narrative paragraph. This narrative writing activity is patterned after the test of spoken English, which uses a picture story. A picture story is a classroom activity where students are tasked to develop a narrative out of the pictures shown or flashed (Shurbaji, 2014). For the sequencing activity, there were five (5) statements that showed a series of events, and the students' task was to arrange the sentences in chronological order. 
The researcher ensured the validity of the test instrument by asking five (5) jurors to validate the test instrument using the Good and Scates' evaluation form. The test questionnaire has an average of 4.82 , which was interpreted as very good. After the test instrument was validated, the researcher secured written permission from the Schools Division Superintendent of Sagay City and the school principal of Sagay National High School to conduct the test.

The data collected from the respondents were subjected to descriptive and comparative analysis. Descriptive analysis was used for data on the level of grammar proficiency and sequencing skills. They needed analysis to describe, show, or summarize the data in a meaningful way. In answering the question on the level of grammar proficiency in terms of subject-verb agreement, tenses of the verb, prepositions, connectors, and the level of sequencing skills of the Grade 7 students, the statistical tool used was mean.

The comparative analysis was used for data to establish a significant difference as they demanded that the data analyzed be generalized so that prediction or decision may be made of the sample. For the statistical tool, the data was subjected to the One-Way ANOVA (Analysis of Variance) for academic performance in English and tracks while the Independent Sample t-Test was used for sex.

Furthermore, this study emphasized the ethical considerations and protocols in conducting the research. The voluntary participation of the respondents was considered important and through informed consent. Lastly, the researcher assured the research participants of the privacy of their identity and other personal information. The researcher followed the approved procedures in conducting the research instrument and maintained objectivity in the analyses and discussions throughout the research study.

\subsection{Results and Discussion}

\section{Level of grammar proficiency}

As indicated in Table 1 , the level of grammar proficiency as a whole $(M=2.28, S D=1.32)$ is low. The students have low mean values in subject-verb agreement $(M=1.88, S D=1.56)$, tenses of the verb $(1.96, S D=1.56)$, and prepositions $(M=2.35, S D=1.58)$, and average mean value in connectors $(M=2.96, S D=1.82)$. This implies that students barely construct sentences in their narrative text with correct subject-verb agreement, consistent tenses of the verb, and correct use of prepositions and connectors. The same difficulties were faced by the respondents of the research studies conducted by Malaca-Sistoza (2016), Hamed (2014), and Fuentes (2011).

Moreover, the results of this study are supported by the findings of Barraquio (2015), which revealed that the grammar proficiency of the students of Letran Calamba College was low. However, this study's results contradict the findings of Fuentes' (2011) study, which revealed that the Sped High School students have a high level of grammar proficiency.

Furthermore, the results of the study, as supported by the related literature, show that students' low grammatical proficiency affects students' ability to write a grammatically correct narrative text. Thus, students have difficulty in writing grammatically correct sentences.

Table 1. Level of grammar proficiency

\begin{tabular}{lcccc}
\hline Track & $\mathrm{N}$ & $\mathrm{M}$ & $\mathrm{SD}$ & Interpretation \\
\hline As a whole & & & & \\
Subject-verb agreement & & 1.88 & 1.56 & Low \\
Tenses of the verb & 308 & 1.94 & 1.56 & Low \\
Prepositions & & 2.34 & 1.58 & Low \\
Connectors & 2.96 & 1.52 & Average \\
Grammar proficiency & 2.28 & 1.31 & Low \\
\hline
\end{tabular}

Mean scale: $0.00-1.20$ very low, 1.21-2.40 low, 2.41-3.60 average, 3.61-4.80 high, 4.81-6.00 very high 
Table 2 shows the level of grammar proficiency of the Grade 7 students when grouped according to academic performance in English. As indicated, outstanding students in English ( $M=3.86, S D=1.43$ ) and very satisfactory students in English $(M=2.64, S D=0.99)$ have high and average level of grammar proficiency, respectively. Other respondents have a low level of grammar proficiency. Outstanding students in English have an average level of proficiency in subject-verb agreement $(M=3.31, S D=1.95)$ and tenses of the verb $(M=3.40, S D=1.96)$ and a high level of proficiency in prepositions $(M=4.38$, $\mathrm{SD}=1.61)$ and connectors $(M=4.36, S D=1.43)$ while the remaining respondents have a level of proficiency ranging from very low to low in the four areas of grammar.

The results signify that while outstanding students in English were able to construct their narrative texts proficiently, very satisfactory, satisfactory, and fairly satisfactory students in English faced minor to major errors in subject-verb agreement, tenses of the verb, and the use of prepositions and connectors. Moreover, the results imply that students' academic performance in English as a whole is greatly influenced by the students' grammatical proficiency.

The results are supported by the studies conducted by Fuentes (2011) and Malaca-Sistoza (2016). The former revealed that the $4^{\text {th }}$ year students found difficulty in the areas of tenses and consistency of the tenses of the verb. In contrast, the latter found out that the Fourth year English major students of the Cagayan State University, Gonzaga Campus have committed major errors in subject-verb agreement. This means that the students found difficulty in constructing texts with correct subject-verb agreement and consistent tenses of the verb.

In addition, the results also imply that students' level of grammar proficiency affects their academic performance in English. This is supported by the statement of Martirosyan et al. (2015) that difficulty in writing using English affects students' academic performance. English 7 follows the prescribed curriculum guide that contains competencies divided into eight domains - reading comprehensions, listening comprehensions, viewing comprehensions, vocabulary, writing and compositions, oral language fluency, and grammar awareness - and grammar is just one among the domains that the teachers assess and evaluate if the students have mastered. As revealed in the results, though grammar is just one of the eight domains, it still affects students' writing proficiency. Indeed, correct use of grammar is the key indicator of academic success (Kello \& Raulerson, 2007).

Table 2. Level of grammar proficiency according to academic performance in English

\begin{tabular}{|c|c|c|c|c|c|c|c|c|c|c|c|c|}
\hline \multirow{2}{*}{ Areas } & \multicolumn{3}{|c|}{ Outstanding } & \multicolumn{3}{|c|}{ Satisfactory } & \multicolumn{3}{|c|}{ Very Satisfactory } & \multicolumn{3}{|c|}{ Fairly Satisfactory } \\
\hline & $\mathbf{M}$ & SD & Int & $\mathbf{M}$ & SD & Int & $\mathbf{M}$ & SD & Int & $\mathbf{M}$ & SD & Int \\
\hline $\begin{array}{l}\text { Subject-verb } \\
\text { agreement }\end{array}$ & 3.31 & 1.95 & Ave & 2.17 & 1.33 & Low & 1.42 & 1.36 & Low & 1.12 & 1.12 & $V L$ \\
\hline $\begin{array}{l}\text { Tenses of the } \\
\text { verb }\end{array}$ & 3.40 & 1.96 & Ave & 2.23 & 1.31 & Low & 1.77 & 1.36 & Low & 1.21 & 1.13 & $\mathrm{VL}$ \\
\hline Prepositions & 4.38 & 1.51 & High & $2 / 75$ & 1.31 & Ave & 2.03 & 1.26 & Low & 1.38 & 1.02 & Low \\
\hline Connectors & 4.36 & 1.61 & High & 3.42 & 1.41 & Ave & 2.68 & 1.25 & Low & 2.23 & 1.25 & Low \\
\hline $\begin{array}{l}\text { Grammar } \\
\text { proficiency }\end{array}$ & 3.86 & 1.43 & High & 2.54 & 0.99 & Ave & 2.05 & 1.08 & Ave & 1.48 & 0.91 & Low \\
\hline
\end{tabular}

Mean scale: 0.00-1.20 Very Low (VL), 1.21-2.40 Low, 2.41-3.60 Average (Ave), 3.61-4.80 High, 4.81-6.00 Very High

As shown in Table 3, females $(M=2.38, S D=1.33)$ are higher than males $(M=2.20, S D=1.31)$ in grammar proficiency. However, both of the sexes have low mean value. Females have an average level in the areas of prepositions $(M=2.45, S D=1.63)$ and connectors $(M=3.16, S D=1.57)$, and a low level in the remaining areas of grammar. On the other hand, males have an average level in connectors $(\mathrm{M}=2.79, \mathrm{SD}=1.46)$ while low in the remaining areas of grammar.

The results show that male students have difficulties in constructing a narrative text with the awareness of grammar rules, resulting in a low level of grammar proficiency. Contrariwise, females have difficulties constructing a narrative text showing correct subject-verb agreement and tenses of the verb resulting in a low level of grammar proficiency. The same results were reflected in the study conducted by Farooq, Uzair-Ul-Hassan, and Wahid (2012). It was found out that both sexes have difficulties in writing due to lack of grammatical proficiency, which, in this current study, is 
classified into a subject-verb agreement, consistent tenses of the verbs, correct use of prepositions, and connectors.

Both sexes have difficulties in writing a narrative text with proficiency in the different areas of grammar. However, this study also found out that females are a bit higher than males in grammar proficiency, which is the same as the findings of the study conducted by Lange, Euler, and Zaretsky (2016) and Zhang (2014), indicating that girls have higher language competence than boys.

Table 3. Level of grammar proficiency according to sex

\begin{tabular}{lccccccc}
\hline \multirow{2}{*}{ Areas } & \multicolumn{3}{c}{ Male } & \multicolumn{3}{c}{ Female } \\
\cline { 2 - 7 } & $\mathrm{M}$ & SD & Int & $\mathrm{M}$ & SD & Int \\
\hline Subject-verb agreement & 1.85 & 1.61 & Low & 1.91 & 1.49 & Low \\
Tenses of the verb & 1.91 & 1.64 & Low & 1.98 & 1.47 & Low \\
Prepositions & 2.25 & 1.52 & Low & 2.45 & 1.63 & Ave \\
Connectors & 2.79 & 1.46 & Ave & 3.16 & 1.57 & Ave \\
Grammar proficiency & 2.20 & 1.31 & Low & 2.38 & 1.33 & Low \\
\hline
\end{tabular}

Mean scale: 0.00-1.20 Very Low (VL), 1.21-2.40 Low, 2.41-3.60 Average (Ave), 3.61-4.80 High, 4.81-6.00 Very High

Table 4 presents the level of grammar proficiency when the students are grouped according to track. As shown, STEM $(M=4.22, S D=1.36)$ and SPA $(M=3.75, S D=1.50)$ have a high level of grammar proficiency. In contrast, STVEP $(M=2.68, S D=0.75)$ and Regular $(M=1.77, S D=1.11)$ have average and low levels of grammar proficiency, respectively. In the area of connectors, STEM has a very high level $(M=5.07, S D=1.15)$, and $S P A$ has a high level $(M=4.55, S D=1.81)$ of proficiency. Both have high proficiency in prepositions, and only the STEM has a high level in tenses of the verb $(M=3.64, S D=1.85)$. Other tracks have a level of proficiency ranging from low to average in the areas of grammar.

The results indicate that STEM and SPA students with high level of grammar proficiency have committed minimal errors in writing their narrative texts. Therefore, students from both tracks grasp the grammar rules and the ability to construct sentences with correct subject-verb agreement, consistent tenses of the verb, and correct use of prepositions and connectors. Meanwhile, STVEP and regular having a low level of grammar proficiency, barely construct their narrative texts due to their difficulties in the specific areas of grammar. The results show that the students from STEM and SPA do better in writing grammatically correct sentences than those from STVEP and Regular. Therefore, more writing and grammar-focused activities should be given to the latter to develop grammar proficiency.

In an investigation on grammar proficiency of UNOR college students, Aboy (2014) found out that the grammar proficiency of the students from the College of Engineering was high. In another study on grammar proficiency, Zhang (2014) found that students from art class were also found to have a high level of grammar proficiency. The findings of the study conducted by Aboy (2014) and Zhang (2014) support the results of this study that STEM students, who are specializing in Engineering and Mathematics, and SPA students, who are specializing in Arts, have a high level of grammar proficiency.

The findings imply that students, regardless of what track they are from, shall have the grammar and language competence to help them express their thoughts, whether in writing and speaking. Language competence shall be emphasized to create and understand newly generated sentences derived from grammatical knowledge (Kyle, 2016). That is why developing students' competence and proficiency in writing is one of the main concerns of ESL Filipino teachers, for excellent communication skills are necessary for this highly competitive world (Aboy, 2014). 
Table 4. Level of grammar proficiency according to track

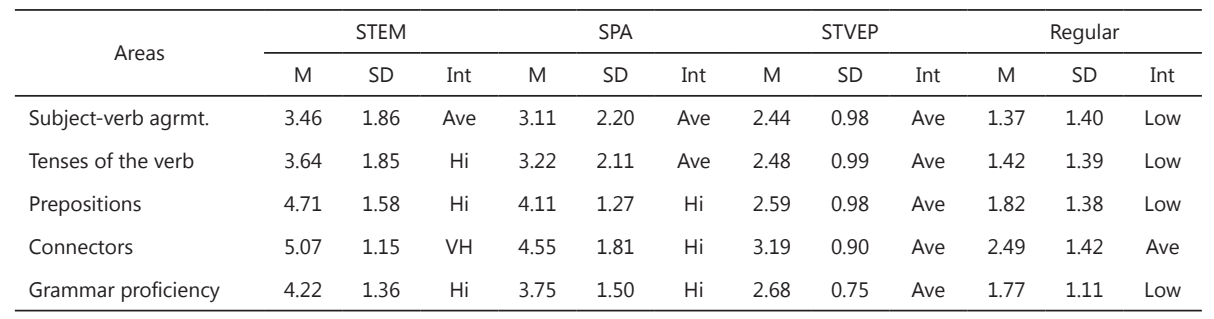

Mean scale: 0.00-1.20 Very Low (VL), 1.21-2.40 Low, 2.41-3.60 Average (Ave), 3.61-4.80 High, 4.81-6.00 Very High

\section{Level of sequencing skills}

Table 5 shows that the students' sequencing skills as a whole are average $(M=3.01, S D=1.57)$. This means that the Grade 7 students wrongly sequenced three particular events in chronological order. When the students are grouped according to academic performance in English, the results show that outstanding students in English $(M=4.38, S D=1.13)$ have a high level of sequencing skills and fairly satisfactory students in English $(M=2.17, S D=1.23)$ have a low level of sequencing skills. Others have an average level.

The results supported the study that probed the students' sequencing skills with high comprehension and low comprehension skills. Gouldthorp, Katsipis, and Mueller (2018) found out that students with high comprehension have a high level of sequencing skills and students with a low level of comprehension have a low level of sequencing skills. High comprehenders produced more accurate sequences than low comprehenders in all the aspects of the sequencing task. Therefore, students' ability to sequence events in a narrative text is an indicator of students' level of comprehension that surely will affect their academic performance in English.

When grouped according to sex, both of the sexes have an average level of sequencing skills. However, females $(M=3.15, S D=1.53)$ are a bit higher than males $(M=2.88, S D=1.53)$, which means that females easily identify the relations between and among the series of events. This finding could be further justified by Zhang's (2014) investigation on the use of connectors in the writings of the students. It was found out that females use logical connectives correctly than males. In relation to the study, females were able to easily sequence events in chronological order. They were able to identify logical connectives to connect a series of events to form a narrative text than males. Students' knowledge is an aid in sequencing a series of events in a narrative text in chronological and logical order.

When categorized according to track, STEM students $(M=4.79, S D=0.50)$ and SPA $(M=3.67$, $M=1.66$ ) have a very high and a high level of sequencing skills, respectively. Contrastingly, the students from the remaining tracks have an average level. STEM is considered to be scientifically and intellectually gifted for subjects offered in the track are advanced, SPA students are considered artistically gifted, STVEP students are technically and vocationally gifted, and general track students are considered generalists. This study's results show that school-labeled intellectually gifted students have a very high level of sequencing skills in narrative writing. The same result was yielded in the study conducted by Abelman (2004), which revealed that school-labeled intellectually and artistically gifted students have higher sequencing skills than students not labeled as such. 
Table 5. Level of sequencing skills

\begin{tabular}{|c|c|c|c|}
\hline Variable & M & SD & Interpretation \\
\hline \multicolumn{4}{|l|}{ Academic performance } \\
\hline Outstanding & 4.38 & 1.13 & High \\
\hline Very satisfactory & 3.42 & 1.45 & Average \\
\hline Satisfactory & 2.86 & 1.61 & Average \\
\hline Fairly satisfactory & 2.17 & 1.23 & Low \\
\hline \multicolumn{4}{|l|}{ Sex } \\
\hline Male & 2.88 & 1.53 & Average \\
\hline Female & 3.15 & 1.62 & Average \\
\hline \multicolumn{4}{|l|}{ Track } \\
\hline STEM & 4.79 & 0.50 & Very High \\
\hline SPA & 3.67 & 1.66 & High \\
\hline STVEP & 2.97 & 1.68 & Average \\
\hline Regular & 2.74 & 1.46 & Average \\
\hline As a whole & 3.01 & 1.57 & Average \\
\hline
\end{tabular}

Mean Scale: 0.01-1.49 Very Low, 1.50-2.49 Low, 2.50-3.49 Average, 3.50-4.49 High, 4.50-5.00 Very High

\section{Difference in the level of grammar proficiency}

As shown in Table 6, there was a significant difference in the level of grammar proficiency $[F(3,304)=53.72, p=0.00]$ and in the areas of subject-verb agreement $[F(3,304)=26.30, p=0.00]$, tenses of the verb $[F(3,304)=26.59, p=0.00]$, prepositions $[F(3,304)=62.49, p=0.00]$, and connectors $[F(3,304)=53.72, p=0.00]$ when grouped according to academic performance.

The $p$-value of the outstanding, very satisfactory, satisfactory, and fairly satisfactory students is $<0.05$, which shows a significant difference in the level of grammar proficiency and the areas of subject-verb agreement, tenses of the verbs, prepositions, and connectors.

Since there was a significant difference, post hoc was made. Utilizing the Scheffe Method, the table of multiple comparisons shows that outstanding students in English differed significantly with very satisfactory, satisfactory, and fairly satisfactory students; very satisfactory students in English differed significantly with satisfactory and fairly satisfactory students; and satisfactory significantly differed with fairly satisfactory students in the level of grammar proficiency and the areas of subjectverb agreement, tenses of the verb, prepositions, and connectors.

This signifies that students, when grouped according to their academic performance in English, differed significantly in their level of grammar proficiency and in the areas of subject-verb agreement, tenses of the verb, prepositions, and connectors. Therefore, the quality of the narrative texts crafted by the students vary and are influenced by their academic performance in English and otherwise. The results of the study further tell us that among the areas in the English subject, the students' grammatical proficiency affects their performance and competence in English.

Trapman's (2018) study on the writing proficiency level and writing development also found the same result that high-achieving students create a significant difference with low-achieving students when it comes to language proficiency in writing, which means high-achieving students were more proficient in writing compared to low-achieving students. Tedick (2010), cited in Laureta (2018), also investigated the significant difference in the grammar proficiency levels of advanced, intermediate, and beginning groups. It was found out that intermediate and advanced groups created a difference with the beginning group showing that the independent variable influenced the dependent variable. These two related studies concurred and agreed with the results that this current study reveals. 
Table 6. Difference in the level of grammar proficiency according to academic performance in English

\begin{tabular}{|c|c|c|c|c|c|}
\hline Academic Performance & $\mathrm{df}$ & $M$ & SD & $\mathrm{F}$ & $p$ \\
\hline \multicolumn{6}{|l|}{ Subject-verb agreement } \\
\hline Outstanding & & 3.31 & 1.95 & & \\
\hline Very Satisfactory & 3,304 & 2.17 & 1.33 & 26.30 & 0.00 \\
\hline Satisfactory & & 1.72 & 1.36 & & \\
\hline Fairly satisfactory & & 1.12 & 1.12 & & \\
\hline \multicolumn{6}{|l|}{ Tenses of the verb } \\
\hline Outstanding & & 3.40 & 1.96 & & \\
\hline Very Satisfactory & 3,304 & 2.23 & 1.31 & 26.59 & 0.00 \\
\hline Satisfactory & & 1.77 & 1.36 & & \\
\hline Fairly satisfactory & & 1.20 & 1.13 & & \\
\hline \multicolumn{6}{|l|}{ Prepositions } \\
\hline Outstanding & & 4.38 & 1.51 & & \\
\hline Very Satisfactory & 3,304 & 2.75 & 1.31 & 62.49 & 0.00 \\
\hline Satisfactory & & 2.03 & 1.26 & & \\
\hline Fairly satisfactory & & 1.38 & 1.02 & & \\
\hline \multicolumn{6}{|l|}{ Connectors } \\
\hline Outstanding & & 4.36 & 1.61 & & \\
\hline Very Satisfactory & 3,304 & 3.42 & 1.41 & 29.31 & 0.00 \\
\hline Satisfactory & & 2.68 & 1.25 & & \\
\hline Fairly satisfactory & & 2.23 & 1.25 & & \\
\hline \multicolumn{6}{|l|}{ Grammar proficiency } \\
\hline Outstanding & & 3.86 & 1.43 & & \\
\hline Very Satisfactory & 3,304 & 2.64 & 0.99 & 53.72 & 0.00 \\
\hline Satisfactory & & 2.05 & 1.08 & & \\
\hline Fairly satisfactory & & 1.48 & 0.91 & & \\
\hline
\end{tabular}

Note: The mean difference is significant at the 0.05 level.

Table 7 shows the results of the independent samples t-test used to determine the significant difference in the level of grammar proficiency of the Grade 7 students when they are grouped according to sex. There was no significant difference in the level of grammar proficiency $[\mathrm{t}(306)=1.15$, $\mathrm{p}=0.25]$ and in the areas of subject-verb agreement $[\mathrm{t}(306)=0.33, \mathrm{p}=0.75]$, tenses of the verb $[\mathrm{t}(306)=0.37, \mathrm{p}=0.71]$, and prepositions [t(306), $\mathrm{p}=0.27]$; however, there was a significant difference in the area of connectors [t(306) $=2.12$. $p=0.03$ ] when grouped according to sex.

The result of the $p$-value in the level of grammar proficiency and the areas of subject-verb agreement, tenses of the verb, and prepositions are greater than 0.05 , and this means that there is no significant difference in the level of grammar proficiency in terms of subject-verb agreement, tenses of the verb, and prepositions when the students are grouped according to sex. This implies that the sex of a person does not greatly affect the proficiency of the students in constructing narrative text with the knowledge of grammatical rules. Though the grammar competence between the males and females varies, both sexes have the same level of grammatical proficiency in narrative writing.

The findings of this study are different from the findings of the study of Farooq, Uzair-Ul-Hassan, and Wahid (2012) on the opinion of second language learners about the writing difficulties in the English language among students in Pakistan. The study indicated a significant difference between the proficiency of students when they were grouped according to sexes. This means that females faced more difficulties in writing using the English language than male students. A significant difference between the sexes was also the result of the study of Lange, Euler, and Zaretsky (2016) on the sex differences in language competence and Barraquio (2015) on grammar proficiency. While Farooq et al. (2012) posited that females faced more difficulties in writing than males showing that males have higher language competence than females, Lange et al. and Barraquio argued that females created a mean difference with males in grammar and language proficiency.

However, the $p$-value of males and females in the area of connectors is $<.05$, which means there is a significant difference in the proficiency in the use of connectors of the students when grouped according to sex. Female students, therefore, significantly differed from men. Females use logical connectives correctly than males (Zhang, 2014). 
Table 7. Difference in the level of grammar proficiency according to sex

\begin{tabular}{|c|c|c|c|c|c|}
\hline \multirow{2}{*}{ Areas } & \multicolumn{2}{|c|}{ Sex } & \multirow{2}{*}{ df } & \multirow{2}{*}{$\mathbf{t}$} & \multirow{2}{*}{$\mathbf{p}$} \\
\hline & Male & Female & & & \\
\hline Subject-verb agreement & $\begin{array}{c}1.85 \\
(1.61)\end{array}$ & $\begin{array}{c}1.91 \\
(1.49)\end{array}$ & & 0.33 & 0.75 \\
\hline Tenses of the verb & $\begin{array}{c}1.91 \\
(1.64)\end{array}$ & $\begin{array}{c}1.98 \\
(1.47)\end{array}$ & & 0.37 & 0.71 \\
\hline Prepositions & $\begin{array}{c}2.25 \\
(1.52)\end{array}$ & $\begin{array}{c}2.45 \\
(1.63)\end{array}$ & 306 & 1.11 & 0.27 \\
\hline Connectors & $\begin{array}{c}2.79 \\
(1.46)\end{array}$ & $\begin{array}{c}3.16 \\
(1.57)\end{array}$ & & 2.12 & 0.03 \\
\hline Grammar proficiency & $\begin{array}{c}2.20 \\
(1.31)\end{array}$ & $\begin{array}{c}2.38 \\
(1.33)\end{array}$ & & 1.15 & 0.25 \\
\hline
\end{tabular}

Note: The mean difference is significant at the 0.05 level.

Table 8 shows the analysis of variance (ANOVA) used to determine the significant difference in the level of grammar proficiency of the Grade 7 students when they are grouped according to track. There was significant difference in the level of grammar proficiency $[F(3,304)=54.28, p=0.00]$ and in the areas of subject-verb agreement $[F(3,304)=27.49, p=0.00]$, tenses of the verb $[F(3,304)=29.86$, $p=0.00]$, prepositions $[F(3,304)=47.18, p=0.00]$, and connectors $[F(3,304)=38.19, p=0.00]$ when grouped according to track.

The p-value among the STEM, SPA, STVEP, and regular students is $<0.05$ which shows a significant difference in the level of grammar proficiency and the areas of subject-verb agreement, tenses of the verbs, prepositions, and connectors. Since there was a significant difference, post hoc was made. Utilizing the Scheffe Method, the table of multiple comparisons shows that STEM significantly differed from the STVEP and Regular, and SPA and STVEP significantly differed from the regular in subject-verb agreement areas and tenses of the verb. For the level of grammar proficiency and in the areas of prepositions and connectors, STEM and SPA significantly differed with STVEP and Regular, and STVEP significantly differed with Regular.

The results imply that the tracks chosen of the students influenced their level of grammar proficiency in terms of subject-verb agreement, tenses of the verb, prepositions, and connectors. Therefore, the students' level of grammar proficiency when grouped according to track varies, showing that a certain group of students needs specific teaching and learning approach, so proficiency in grammar and writing will be developed. Such findings are congruent to the findings of the research study conducted by Aboy (2014), which revealed that criminal justice education students differed significantly from the students from other colleges. Thus, the course chosen affected their level of grammar proficiency. Indeed, varied teaching strategies are needed to address the students' specific needs and difficulties.

Meanwhile, different results yielded in the study probed by Barraquio (2015) on the grammar proficiency of Colegio de San Juan de Letran Calamba students. In the investigation, the researcher found out that there was no significant difference in the students' level of grammar proficiency when grouped according to the degree of programs. But, the Engineering students' mean value was a bit higher compared to the mean values of the other programs. This means that the chosen program of the college students did not significantly affect and influence their proficiency in grammar. Pablo and Lasaten (2018) also noted in the results of their study on writing difficulties and the quality of academic essays of students that students from specialized programs created a difference from students from non-specialized programs, which would mean that the former have a better quality of writings than the latter. 
Table 8. Difference in the level of grammar proficiency according to track

\begin{tabular}{|c|c|c|c|c|c|}
\hline Track & df & $\mathrm{M}$ & SD & $\mathrm{F}$ & $\mathrm{p}$ \\
\hline \multicolumn{6}{|c|}{ Subject-verb agreement } \\
\hline STEM & & 3,46 & 4.86 & & \\
\hline SPA & 3,304 & 3.11 & 2.20 & 27.49 & 0.00 \\
\hline STVEP & & 2.44 & 0.98 & & \\
\hline Regular & & 1.37 & 1.40 & & \\
\hline \multicolumn{6}{|c|}{ Tenses of the verb } \\
\hline STEM & & 3.64 & 1.85 & & \\
\hline SPA & 3. 304 & 3.22 & 2.11 & 29.86 & 0.00 \\
\hline STVEP & & 2,48 & 0.99 & & \\
\hline Regular & & 1.43 & 1.39 & & \\
\hline \multicolumn{6}{|c|}{ Prepositions } \\
\hline STEM & & 4.71 & 1.58 & & \\
\hline SPA & 3,304 & 4.11 & 1.27 & 47.18 & 0.00 \\
\hline STVEP & & 2.60 & 0.98 & & \\
\hline Regular & & 1.82 & 1.38 & & \\
\hline \multicolumn{6}{|c|}{ Connectors } \\
\hline STEM & & 5.07 & 1.15 & & \\
\hline SPA & 3,304 & 4.56 & 1.81 & 38.19 & 0.00 \\
\hline STVEP & & 3.19 & 0.90 & & \\
\hline Regular & & 2,49 & 1.42 & & \\
\hline \multicolumn{6}{|c|}{ Grammar proficiency } \\
\hline STEM & & 4.22 & 1.36 & & \\
\hline SPA & 3,304 & 3.75 & 1.50 & 54.28 & 0.00 \\
\hline STVEP & & 2.68 & 0.75 & & \\
\hline Regular & & 1.78 & 1.11 & & \\
\hline
\end{tabular}

Note: The mean difference is significant at the 0.05 level.

\section{Difference in the level of sequencing skills}

Table 9 shows a significant difference in the sequencing skills $[F(3,304)=16.48$. $p=0.00]$ of the students when they are grouped according to academic performance in English. The $p$-value of the outstanding, very satisfactory, satisfactory, and fairly satisfactory students is $<0.05$ which shows a significant difference. With this, post hoc was utilized. Using Scheffe Method, the results revealed that outstanding students significantly differed from very satisfactory, satisfactory, and fairly satisfactory students. Very satisfactory and satisfactory significantly differed from fairly satisfactory in the level sequencing skills. This implies that students with satisfactory to outstanding English performance have the ability and skills to logically sequence their thoughts and ideas. Further, the results of the study tell us that the sequencing skills of the students have a great impact on their performance in the English subject. Hereby, activities to be given to the students should gear them towards developing a specific skill so performance in the subject would be improved.

The result is supported by Gouldthorp, Katsipis, and Mueller (2018) whose study found out that students with high comprehension create a difference with a low level of comprehension in the sequencing skills. Thus, the result of the study yielded that there was a significant difference in the sequencing skills of the students when grouped according to comprehension levels. The findings also suggest that students' difficulties in sequencing events in logical and chronological order are due to their inability to comprehend the representations of event structure and the lack of knowledge of connectors to tie up series of events (Pyykkonen \& Jarvikivi, 2012). 
Table 9. Difference in the level of sequencing skills according to academic performance in English

\begin{tabular}{llllll}
\hline Academic Performance in English & $\mathrm{df}$ & $\mathrm{M}$ & $\mathrm{SD}$ & $\mathrm{F}$ & $\mathrm{p}$ \\
\hline Outstanding & & 4.38 & 1.13 & & \\
Very Satisfactory & 3,304 & 3.42 & 1.45 & 16.48 & 0.00 \\
Satisfactory & & 2.86 & 1.61 & & \\
Fairly Satisfactory & & 2.18 & 1.23 & & \\
\hline
\end{tabular}

Note: The mean difference is significant at the 0.05 level.

As indicated in Table 10, there is no significant difference in the level of sequencing skills $[t(306)=1.50, p=0.14]$ of the students when they are grouped according to sex. The $p$-value of males and females is greater than 0.05 , which means that the null hypothesis is accepted. Accordingly, females do not significantly differ from males. This implies that sex does not influence the skills of the students to sequence a series of events in chronological order. There may be a slight difference in the ability of male and female students to sequence events. However, the results tell us that the students coming from both sexes are not far apart when it comes to the ability to sequence events chronologically.

Hamed (2014) once posited that students have the greatest difficulty in using connectives, which is reflected in how students organize their ideas in the text. It is also supported by Pablo and Lasaten (2018). They investigated students' writing quality and found out that both males' and females' writings have no sense of logical sequence. Thus, the sequencing skills in writing any texts of the students do not vary greatly when they are compared according to sex.

Table 10. Difference in the level of sequencing skills in terms of sex

\begin{tabular}{llllll}
\hline Sex & M & SD & df & T & $p$ \\
\hline Male & 2.88 & 1.53 & & & \\
& & & 306 & 1.50 & 0.14 \\
Female & 3.15 & 1.62 & & & \\
\hline
\end{tabular}

Note: The mean difference is significant at the 0.05 level.

Table 11 presents the Analysis of Variance (ANOVA) used to determine the significant difference in the level of sequencing skills of Grade 7 students when they are grouped according to track. The $\mathrm{p}$-value of STEM, SPA, STVEP, and regular is $<0.05$. Therefore, there is a significant difference in the level of sequencing skills $[F(3,304)=16.58, p=0.00]$ of the Grade 7 students when they are grouped according to track. Using the Scheffe method, the table of multiple comparisons revealed that STEM significantly differed with STVEP and regular, which means that the sequencing skills of the STEM students are better than the sequencing skills of STVEP and regular students.

Abelman (2004) and Zhang (2014) have also found the same results. Both investigated the sequencing skills of the students from special and non-special classes. The results showed that students from special classes are better in sequencing and the use of connectors compared to students from non-special class. Thus, the narrative texts made by students from special classes are more coherent than the narrative texts made by students from non-special classes. As supported by the related literature, the results imply that the track influenced the sequencing skills of the students. Hence, the students should be immersed in varied sequencing activities based on the students' ability and needs. In this way, improvements in the target skills will be fostered. 
Table 11. Difference in the level of sequencing skills in terms of track

\begin{tabular}{|c|c|c|c|c|c|}
\hline Track & $d f$ & $\mathrm{M}$ & SD & $\mathrm{F}$ & $p$ \\
\hline STEM & & 4.79 & 0.50 & & \\
\hline SPA & 3,304 & 3.67 & 1.66 & 16.58 & 0.00 \\
\hline STVEP & & 2.97 & 1.68 & & \\
\hline Regular & & 2.74 & 1.46 & & \\
\hline
\end{tabular}

Note: The mean difference is significant at the 0.05 level.

This study theorized that grammar proficiency and sequencing skills are factors of success in narrative writing. The claim is supported by the findings that this study revealed. Students who were found to have a high level of grammar proficiency and sequencing skills successfully crafted their narrative texts. As explained in Michael Halliday's Theory of Functional Grammar (1973) and Chomsky's Transformational - Generative Grammar Theory (1956), written texts are understood easily when the elements of each sentence are systematically organized. This is achieved when the students grasp the grammar rules and the ability to sequence ideas logically.

\subsection{Conclusion}

A low level of grammar proficiency and the average level of sequencing skills in narrative writing could be attributed to students' lack of knowledge in grammatical rules and ability to sequence ideas and series of events logically and chronologically. Such students' difficulty will be addressed if there are specific grammar and sequencing activities that cater to the students' diverse needs.

Moreover, students' grammar proficiency and sequencing skills vary depending on their academic performance in English and track. This implies that the students whose English performance is low and very satisfactory need simplified instructions, and students from different tracks need differentiated instructions and activities from the teachers. To sustain and improve the grammar proficiency and sequencing skills of the students who perform well in the subject, there shall be extra activities to be given to the students based on their level of proficiency and competence.

Furthermore, grammar proficiency and sequencing skills are factors of success in narrative writing. This study has found out that students who grasp the grammar rules and the ability to sequence ideas logically and chronologically are the ones who have successfully written their narrative texts. Written texts are understood easily when the elements of each sentence are systematically organized for meaning is constructed out of semantic, syntactic, and pragmatic functions.

Lastly, the results of the study would serve as a basis for the instructional leaders to come up with specific classroom strategies and diverse instructional materials that teachers will use to cater to the needs and address the difficulty of the students coming from different sections, classes, and specializations when it comes to grammar proficiency and sequencing skills in writing. This study contributes to learner corpora research and fills in the gap in the scarce literature that focuses on the writing and grammar proficiency of high-achieving and low-achieving students.

\section{REFERENCES}

Abelman, R. (2004). TV Literacy and Academic/Artistic giftedness: Understanding time leaps and time lags. Roeper Review, 26(2), 8589. Retrieved from http://search.proquest.com/docview/206697857/912C2FCAA7B84F4FPQ/76?accountid=34542

Aboy, I. G. (2014). Grammar proficiency in the communicative context of fourth year college students (Unpublished master's thesis). University of Negros Occidental - Recoletos, Bacolod City.

Anierdes, M. C. (2015). The level of English proficiency of Grade 7 students (Unpublished master's thesis). University of Negros Occidental - Recoletos, Bacolod City.

Apsay, A. P. (2008). Written English proficiency of college education students: Basis for a developmental written English training program. (Unpublished master's thesis). University of Negros Occidental - Recoletos, Bacolod City.

Baniaga, H. M. L. (2008). Grammatical competence of freshmen college students of Baguio Central University. Retrieved from http:// www.eisrjc.xom/journals/journal_1/bsu-2008-7pdf

Barraquio, D. T. (2015). Grammar Proficiency of Colegio de San Juan de Letran Calamba College Students. NEXO, 1(1). Retrieved from http://ejournals.ph/form/cite.php?id=6780

Bar-On, D. (2004). Semantic eliminativism and the theory-theory of linguistic understanding. Retrieved from https://search.proquest. com/docview/195308304?accountid $=34542$ 
Buasen, Y. (2008). Grammatical competence of _college freshmen of Benguet State University. Retrieved from http://www.eisrjc.xom/ journals/journal_1/bsu-2008-7pdf

Chan, A.Y.W. (2010). Toward a taxonomy of written errors: Investigation into the written errors of Hong Kong Cantonese ESL learners. TESOL Quarterly, 44(2), 295-319. Retrieved from https://www.researchgate.net/publication/261779350_Toward_a_Taxonomy_ of Written_Errors Investigation_Into the Written_Errors_of Hong_Kong_Cantonese_ESL_Learners

Chomsky, N. (1960). Tool Module: Chomsky's Universal Grammar. Retrieved from http://thebrain.mcgill.ca/flash/capsules/outil_ rouge $06 . \mathrm{html}$

Dalisay, A. M., Luzada, M. G., Ong, M. R., \& Santos, J. (2013). Grammar and composition in our changing world 3. Mandaluyong City, Philippines: Anvil Publishing, Inc.

Department of Education-Bureau of Learning Resources. (2018). English learner's material. Pasig City., Philippines: FEP Printing.

Dipolog-Ubanan, G. (2016). L1 influence on writing in L2 among UCSI Chinese students: A case study. Pertanika Journal of Social Sciences and Humanities, 24(4), 1835-1847.

Farooq, M. S., Uzair-Ul-Hassan, M., \& Wahid, S. (2012). The opinion of second language learners about writing difficulties in the English language. South Asian Studies, 27(1), 183-194. Retrieved from https://search.proquest.com/ docview/1023239824?accountid $=34542$

Fuentes, C. M. (2011). English proficiency of fourth year students of Sped High School. (Unpublished Master's Thesis). Philippine Normal University - Visayas.

Ghasemi, M. (2013). An investigation into the use of cohesive devices in second language writings. Theory and Practice in Language Studies, 3(9), 1615-1623. doi:http://dx.doi.org/10.4304/tpls.3.9.1615-1623

Gouldthorp, B., Katsipis, L., \& Mueller, C. (2018). An investigation of the role of sequencing in Children's reading comprehension Reading Research Quarterly, 53(1), 91-106. Retrieved from doe: http://dz.doi.org/10.1002/rrq.186

Halliday, M.A.K. (1994). Information on Systemic Functional Linguistics. International Systemic Functional Linguistics Association Retrieved 1 July 2011.

Hamed, M. (2014). Conjunctions in argumentative writing of Libyan tertiary students. English Language Teaching, 7(3), 108-120.

Hummel, K. M. (2009). Aptitude, phonological memory, and second language proficiency in novice adult learners. Applied Psycholinguistics, 30(2), 225-249. Retrieved from doi:http://dx.doi.org/10.1017/S0142716409090109

Karlsen, J., Geva, E., \& Lyster, S. (2016). Cognitive, linguistic, and contextual factors in Norwegian second language learner's narrative production. Applied Psycholinguistics, 37(5), 1117-1145. Retrieved from doi:http://dx.doi.org/10.1017/S014271641500051X

Lahuerta, A. C. (2018). Study of accuracy and grammatical complexity in EFL writing. International Journal of English Studies, 18(1), 71-89. Retrieved from doi:http://dx.doi.org/10.6018/ijes/2018/1/258971

Lange, B. P., Euler, H. A., \& Zaretsky, E. (2016). Sex differences in language competence of 3- to 6-year-old children. Applied Psycholinguistics, 37(6), 1417-1438. doi:http://dx.doi.org/10.1017/S0142716415000624

MacMillan, G. (2014)/ Importance of grammar. Retrieved from https://www.linkedin.com/pulse/importance-grammar-punctuationspelling-gregg-macmillan

Malaca-Sistoza, J. (2016). English sentence construction ability of the students. International Journal of Advanced Research in Management and Social Sciences ISSN: 2278-6236 Retrieved from http://www.garph.co.uk/IJARMSS/June2016/35.pdf

Maniego, K. G. (2016). Syntactic complexity in the written composition of senior high school students. (Unpublished master's thesis) University of Negros Occidental - Recoletos, Bacolod City.

Pablo, J.C.I \& Lasaten, R. C. S. (2018). Writing Difficulties and Quality of Academic Essays of Senior High School Students. Asia Pacific Journal of Multidisciplinary Research. Vol. 6 No.4, 46-57.

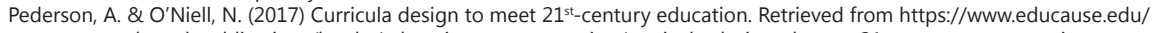
research-and-publications/books/educating-net-generation/curricula-designed-meet-21st-century-expectations

Pinheiro, Marcia. (2016). Universal Grammar. International Journal for Education Innovation and Research. Retrieved from https:// www.researchgate.net/publication/302590438_Universal_Grammar

Prieto, N. G. (2017). Practical research. Quezon City: Lorimar Publishing, Inc

Rajaendram, R. (2015). Speaking the global language. Retrieved from https://www.thestar.com.my/news/education/2015/08/09/ speaking-the-global-language

Shanklin, T. (1994). The communication of grammatical proficiency. Retrieved from https://shanklin.sdsu.edu/Linguistics/ CommunicationL.pdf

Shurbaji, E. (2014). Photo narratives. Retrieved from http://medium.com/learning-journalism-tech/photo-narratives-d77b812f99dd

Sevilla, C. G. (1998). Research methods. Quezon City: Rex Printing Company, Inc.

Stephens, A. (2018). Narrative writing. Retrieved from https://lps.lexingtonma.org/Page/2254

Zhang, R. (2014). A corpus-based comparative study of lexical proficiency of writings by majors of arts vs. those of science. Theory and Practice in Language Studies, 4(4), 743-749. Retrieved from https://search.proquest.com/ docview/1519975887?accountid $=34542$

\section{Correspondence:}

LESTER JOHN T. QUIJANO

lesterjohn.quijano@deped.gov.ph

https://orcid.org/0000-0002-1364-5946

MA. JUDY B. LEGASPI

mariajudy2012@yahoo.com 